\title{
THE COHESION OF PROLOGUE ON THE HUNGER GAMES TRILOGY: A DISCOURSE ANALYSIS
}

\author{
Ann MelleneCapuyFernandico \\ Visayas State University \\ mellenecapuyfernandico@gmail.com
}

\begin{abstract}
Cohesion is designed to deal with words and phrases that generates a pattern of relations between lexical elements and structures to build an integral and logical text. Accordingly, this research identifies how the language is used in the prologue of the Hunger Games Trilogy by Suzanne Collins. The method of this research is a discourse analysis focusing on Systemic Functional Linguistics (SFL) developed by M.A.K. Halliday.Based on the result of the analysis, the prologue of The Hunger Games and Catching Fire novels can be described in the terms of field, tenor, and mode creating the contextual parameter. The result also shows that the text of the novels is written and is clearly detached, explicit, planned and integrated. While links were observed as characters and places were repeatedly written. It can also be drawn that the two novels aim to tell a story. Furthermore, the texts do not instruct the reader on what to do but rather, it tells what the characters of the story did, are doing, or will do. The novels also implore the readers to read further beyond the prologue and to the main story.
\end{abstract}

Keywords: cohesion, discourse analysis, hunger games, sfl

\section{Introduction}

Every text whether spoken or written is a discourse and it comprises sentences. Discourse is a use of language above and beyond the sentence level, and the purpose of a text is to pass on information or communicate with the reader or the receiver of the text. It is the study of words that communicate some information: structure, theme, meaning, and rhetorical devices (Hardison, 2011).

The structure of discourse can be analyzed in terms of two features namely Cohesion and Coherence. Cohesion is related to the way in which different textual units are linked together to form a higher unit. Coherence on the other hand, is concerned with the linking of communicative acts. Any text whether spoken or written, contains both cohesion and coherence

Cohesion is broadly categorized into two types - Grammatical cohesion and Lexical cohesion. Both grammatical and lexical elements together contribute to the cohesion of a text. Cohesion is mainly concerned with extended discourse rather than with individual sentence (Flowerdew, 2013). Cohesion is also designed to deal with words and phrases that generate a pattern of relations between lexical elements and structures to build an integrated and logical text (Trebits, 2009). In what follows, an analysis of cohesion aims to connect central concepts to the context of academic writing intended to pursue standards of communication, writing styles, textuality, and a practice of discourse.

In this sense of relationship, reference is defined as cohesive devices in a text that can only be interpreted to some other parts of the text or to the world experienced by the sender and the receiver of the text. Substitution outlines the use of pro-forms to represent previously mentioned entities or events in the form of types of nominal, verbal and clausal substitutions. Ellipsis is the omission of clauses, phrases or words that can be recovered from other parts of the discourse. Conjunction is a device for marking logical relationships in a discourse. Lexical cohesion is a linguistic device that occurs when two words in a text are related in terms of their meaning. Lexical cohesion takes the form of (a) reiteration: repetition, synonyms or near-synonym, superordinate and general word; and (b) collocation: the regular pattern of partnerships between words and intersentence semantic ties (Halliday, 1994; Halliday\&Hasan, 1976; Johnson, 1992; Alotaibi, 2015\& Wales, 2001).

In comprehending cohesion, learners can practice interpreting what pronouns refer to in the context, what the conjunction relationships between sentences are and how different words are used to refer to the same idea (Nation, 2009). In other words, cohesion is contextually 
used involving pronouns reference, and conjunction relationships to connect ideas in words, phrases and sentences.

For the past years several studies on the analysis of cohesion have been conducted by many researchers. One paper by Hind Tahseen Hameed (2008) analyzes an English text from a magazine for the purpose of identifying cohesive elements in texts. The result of his research shows what principles exist that create semantic links within text between sentence and paragraph boundaries. It also shows how cohesion in texts creates one kind of texture through the ties that coordinate ideas and experiences.

Another research paper by Afnan Bahaziq (2016) defines and describes the cohesive devices used in the students' essay writing. The analysis of the written discourse was based on the work of Haliday and Hassan (1976), and the results show that the students' writing shows clear evidence of cohesion and demonstrates the use of grammatical and lexical devices.

Additionally, another paper by Emi Emilia et al. (2018) reports on the result of a study that aims to investigate the cohesion of exposition texts written by eleventh graders in a school in Badong, West Java, Indonesia. The study used a qualitative case study research design involving 32 students. The results of the case study show that all text written by the students show all elements of an exposition, including thesis, arguments, and restatement of the thesis. The results also indicate, to some extent, students grasp and understanding of the demand of the generic form of an academic exposition genre, to achieve the purpose and the function of the genre.

For this study, the researcher analyzes the prologue of the novels The Hunger Game and Catching Fire, a series of young adult dystopian novel written by Suzanne Collins. This research will be useful in identifying how the language is used in the prologue of these two novels which are well received by the young readers.

Generally this study aims to analyze the cohesion found in the prologue. Specifically, this study aims to (1) analyze deeper the references, conjunction, and lexical cohesion in the prologue; and (2) understand the intention that the writer of the prologue has in the particular arrangement or structure of words and how they are used.

\section{Method}

This study analyzes cohesion found in the prologue of the Hunger Games Trilogy by Suzanne Collins. In order to analyze the links between texts, the researcher used Systemic Functional Linguistics. Systemic Functional Linguistics (SFL) is a theory of language and discourse developed by M.A.K. Halliday and his followers. Systemic Functional Linguistics is a theory of language centered around the notion of language function. It accounts for the syntactic structure of language, and it places the function of language as central, in preference to more structural approaches, which place the elements of language and their combination as central. SFL starts at social context, and looks at how language both acts upon, and is constrained by this social context (Halliday, 1994).

Systemic in SFL refers to a conception of language as a network of systems, or choices, for expressing meaning. Functional refers to a concern for what language does and how it does it, in contrast to more structural approaches (Flowerdew, 2013).

Additionally, applying M.A.K. Halliday's Systemic Functional Linguistics, the researcher used the three metafunctions (Ideational, Interpersonal, and Textual) in identifying the why and what about the text indicates.

Moreover, in conducting this research the researcher used Qualitative Content Analysis design. The qualitative content analysis was the most appropriate research design to be applied in this study since it aims at analyzing thoroughly and interpret text data to draw inference towards the text of the prologue.

The data source of this research was taken from the books The Hunger Games and Catching Fire by Suzanne Collins. The two novels are part of the Hunger Games Trilogy, which are both New York Times best sellers. The Hunger Games is the first book in the series and was released on September 14, 2008. On the other hand, the second instalment of the series, Catching Fire was released on September 1, 2009. Both books were received well by the readers and kick started a global phenomenon.

\section{Findings and Discussion}

Based on the analysis, the researcher analyzed the cohesion found on the prologue of Hunger Games Trilogy by applying Systemic Point of View of SFL and Functional Approach of SFL using the three metafunctions (ideational, interpersonal, and textual).

\section{Systemic Functional Linguistics}

. Applying the systemic point of view in SFL, the researcher discovered that the first message of the prologue of The Hunger Games and Catching Fire are both Indicative which means that the texts try to point out or indicate a message. However, they differ due to The Hunger Games taking an Interrogative 
approach, specifically, Closed Interrogative wherein the question can be answered with either a yes or no but pushes the readers to think about the question before answering and moving on to the next paragraph.

\section{Figure 1.First Phrase of the Hunger Games}

$$
\begin{aligned}
& \text { Could you survive on your own in the } \\
& \text { wild, with everyone out to make sure } \\
& \text { you don't live to see the morning? }
\end{aligned}
$$

The first phrase of The Hunger Games has three metaphorical sentences where in the first two are both related to fire in relation to the title with the last sentence as a metaphor of the group for an individual. Each sentence indicates the effects caused by the events that occurred in the first book and the situation that occurs as the book begins. The three sentences are all Declarative.

\section{Figure 2.First Phrase of Catching Fire}

$$
\begin{aligned}
& \text { Sparks are igniting flames are } \\
& \text { spreading and the capitol wants } \\
& \text { revenge. }
\end{aligned}
$$

Applying the functional approach of SFL, the researcher used the three metafunctions (Ideational, Interpersonal, and Textual) in identifying the why and what about the text indicates. The ideational metafunction is concerned with things (real or imagined) in the world. The interpersonal function has to do with relationships between participants, not only in spoken texts, but also in written texts (with regard to how the writer interacts with the reader). The textual metafunction relates to the construction of text, how it is held together and what gives it texture (Flowerdew, 2013).

Beginning with the ideational metafunction (field), the researcher identified the field using the process types present in the prologues. There are six process types and these are relational, material, behavioral, mental, existential, and verbal. However, the only process types present in the texts are material, behavioral, relational, and existential; with the majority as the material process type followed by behavioral, then relational and the least being existential in both prologues.

Therefore, with the four process types present in the prologue, it can be said that the prologue was written in order to identify what the characters and participants in the text are doing and what is happening before the story began and the possible events that could take place as the story begins. Additionally, it also implies the behaviors of the characters, the existence of certain people, places and events, and the actions being done.

The interpersonal metafunction (tenor), seeks to identify who the writer is to the reader and vice versa. The prologues are both written in third person with The Hunger Games having one interrogative sentence however, it is clearly used to engage the readers. Basically, majority of the texts are declarative. Since the prologues were written in this way, it shows no relation between the writer and the reader. It also shows that the text is written to be less personalized gathering the attention of no specific audience (or in this case, reader). The writer also shows enough confidence on the knowledge he/she has about the book by not using any modal verbs.

Lastly in the SFL theory is the Textual metafunction (mode) which focuses in the construction of the text. The prologues in both The Hunger Games and Catching Fire are both structured closely similar to the other and both created Cohesion. The prologue in The Hunger Games is basically formed with subjects, majority being Katniss Everdeen and twice mentioned was the Capitol and the Hunger Games. Meanwhile, in the Catching Fire prologue, the whole text revolves not only on Katniss, the Capitol, and the Hunger Games but also on new characters such as Peeta and Gale. Additionally, the rebellion was also mentioned twice however it was only on the first paragraph of the prologue.

\section{Cohesion in the Prologue}

Cohesion is concerned with the formal and semantic links between clauses. Cohesion has five cohesive devices: reference, substitution, ellipsis, conjunction, and lexical cohesion (Flowerdew, 2013). For this study the researcher only applies reference, conjunction and lexical cohesion in order to find links on the prologues due to the absence of substitution and ellipsis in the text.

Reference is a word or phrase wherein its identity can be determined by referring to other parts of the text or the situation. On the other hand, conjunction is a cohesive device wherein the meaning relation is contained in the cohesive item itself. There are four types of conjunction and these are: additive, adversative, causal, and temporal. In The Hunger Games prologue, the most referred to would be the noun Katniss Everdeen which is linked to every sentence in the second paragraph however it does not occur in other paragraphs or in the phrase. The second most written reference would be the nation of Panem and the annual Hunger Games which is linked to three. The text consists of two adversative conjunction references. Furthermore, there are no present 
substitution and ellipsis in the text. Figure three below shows the references found in The Hunger Games novel.

\section{Figure 3.The Hunger Games Prologue}

COULD YOU SURVIVE ON YOUR OWN, IN THE WILD, WITH EVERY ONE OUT TO MAKE SURE YOU DON'T IIIE TO SEE THE MORNING?

In the ruins of a place once known as North America lies the nation of Panemin, a shining Capito sorrounded by twelve outlying districts. The Canitol' is harsh and cruel and keeps the districts in line by forcing them aly to send on 5 boy and on $<$ giry yetween ages of twelve and eighteen to participate inthe annual Hunger Games, a fight to the death on live TV.

Sixteen-year-old cKatniss Everdeet who lives alone witherm motherland younger sister) regards it as a death sentence whe shi steps forward to take-het sister's place in the Games, But Ratniss bas been close to dead before - and survival for he is second nature. Without really meaning to, she becomes a contender. But if she is to win, She will have to start making choices that weigh survival against humanity and (iire) against love.

Acclaimed writer SUZANNE COLLIN, author of The New York Times bestselling Underland Chronicles, delivers equal parts [uspense-and philosophy adventureand romance in this novel set in a future with unsettling parallels to out present.

In analyzing the lexical cohesion there will be two subcategories to consider; reiteration and collocation. Reiteration of a lexical item may be by repetition, use of a synonym, a near synonym, and a superordinate or the general class words. In the text, the only types of reiteration present are repetition and near synonym. For repetition, the lexical item repeated were you, her, and she. Furthermore, the only lexical item having near synonyms present in the text are close to dead and survival.

On the other hand, collocation can be words related with each other semantically without being referring to the same thing. Thus, there is cohesion between any pair of lexical items that stand to each other in some recognizable lexicosemantic (word meaning) relation (Flowerdew, 2013). Collocation has two systems operating; hyponymy and antonymy. In the text, the lexical items under hyponymy are mother, sister - family and suspense, philosophy, adventure, romance - genre. The types of antonymy present in the prologue are boy and girl, and death and life.

However, in Catching Fire, the reference that is most referred to is still Katniss Everdeen, a noun present in all the paragraphs but not in the beginning phrase. It is followed by the reference Katniss and Peeta which is linked to four. The prologue also contains one additive conjunction reference; and, one adversative conjunction reference; yet, and one causal conjunction reference; if. It does not contain substitution and ellipsis. The figure below shows the references found in the Catching Fire novel.

\section{Figure 4.Catching Fire Prologue}

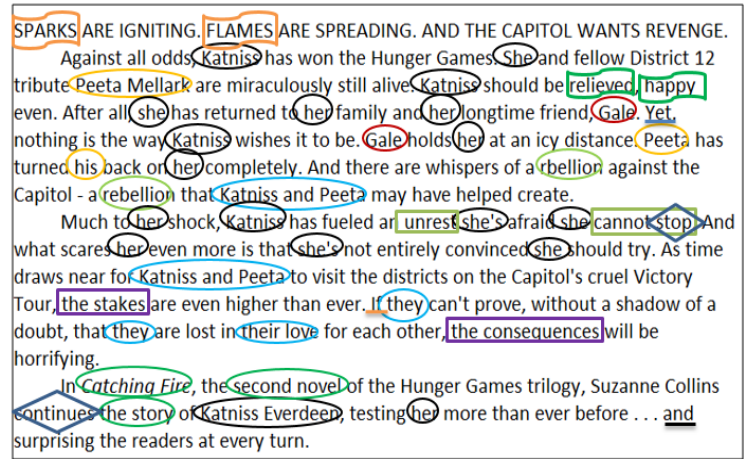

For its lexical cohesion on reiteration, the lexical items repeated are Katniss, Katniss and Peeta, Gale, she, her, and they. While on near synonyms, there are two pairs, the lexical items unrest and cannot stop, and the stakes and the consequences. The lexical cohesion on collocation regarding hyponymy are relieved, happy - positive emotions, and sparks, flames fire. Furthermore, the only lexical items on antonym are stop and continue.

Based on the results, it is clear that Katniss Everdeen is the main reference of the story. Since the noun Katniss Everdeen is the main reference it can be depicted that the novel is based on the reference's point of view. If one reads the novel, it is understood that the story uses first person point of view within the perspective of the main protagonist, Katniss Everdeen.

In reading the text carefully, it can be observed that the prominent references in both prologues are Katniss Everdeen, The Hunger Games, and theCapitol. The whole trilogy revolves around the three main references wherein Katniss Everdeen is the protagonist with the event being the Hunger Games while the antagonist is a government organization called the Capitol. It can also be observed that the names of Peeta and Gale only came up on the second book of the trilogy and in reading the book, the reader can find out that Peeta and Gale were not even highlighted in the story before the book Catching Fire wherein their perspectives and actions were given more attention, however, it is still based on Katniss' perspective and thoughts.

To sum it up, the Systemic Functional Linguistic Theory of the prologues of both novels can be described in the field, tenor, and mode creating the contextual parameter. The field is about Katniss Everdeen and the description of the Hunger Games. The tenor is how the novel is fictional, a text and the writer to reader relationship (neither know each other). The mode is that the text is written to be read and is descriptive. On the other hand, the lexicogrammar is composed of the process types, use of pronouns, modality markers, and cohesion. The process types are mostly material, indicating the happenings and the characters (beings) in the text. The text is written and is clearly detached, explicit, planned and integrated. While links were observed as characters and places were repeatedly written.

\section{Conclusion}

To conclude, the prologue in the books The Hunger Games and Catching Fire of the trilogy by Suzanne Collins aim to tell a story. Specifically, it introduces the beginning of the 
book and (based on Catching Fire) connects the story from the events that occurred in the first book. There were several interconnected lexical items that enabled the understanding of the text and several similarities between the prologue of The Hunger Games and Catching Fire especially in their structure, the types of processes present and the interpretation of the text is closely related. Furthermore, the texts do not instruct the reader on what to do but rather, it tells what the characters of the story did, are doing, or will do. It also implores the reader to read further beyond the prologue and to the main story.

\section{References}

Alotaibi, H. (2015). The Role of Lexical Cohesion in Writing Quality. Journal of Applied Linguistics \& English Literature.

Bahaziq, Afnan (2016). Cohesive Devices in Written Discourse: A Discourse Analysis of a Student's Essay Writing.English Language Teaching. Canadian Center of Science and Education. Vol. 9, No. 7, 2016. 1916-4742

Brown, D. (2019, September 25). MASTERCLASS. Retrieved November 23, 2019, from masterclass.com:

https://www.masterclass.com/articles/writin g-101-what-is-a-prologue\#quiz-0

Emilia, Emi et al. (2018). An Analysis of Cohesion Exposition Tests: An Indonesian Context. Indonesian Journal of Applied Linguistics, Vol 7. No. 3

Flowerdew, J. (2013). In J. Flowerdew, Discourse in English Language Learning (pp. 13-14). New York City: Routledge.

Halliday, M.A.K. and Hasan, R. (1976). Cohesion in English: Longman group Ltd

Halliday, M.A.K. (1994). An Introduction to Functional Grammar. London: Edward Publisher Ltd.
Halliday, M.A.K. and Hasan, R. (1989). Language, Context and Text: Aspects of Language in a Social Semiotic Perspective. 2nd ed. Oxford: OUP.

Hammed, Hind Tahseen (2008). Cohesion in Text: A Discourse Analysis of News Article in a Magazine. Diyola University/College of Education. AL-Faith Journal No. 37.

Hardison, Karen P.L.(2011). Text and DiscourseeNotes Editorial, 6 Aug. 2011.

Mansfield, K. (2015). An Introduction to Genre Analysis. In K. Mansfield.

Trebits, A. (2009). Conjunctive cohesion in English language EU documents: A corpus-based analysis and its implications, English for Specific Purposes, 28, 199- 210 